\title{
Devices and Techniques for Blood Pressure Measurement and Criteria for Hypertension Adopted by Brazilian Physicians. Exploratory Study
}

\author{
Décio Mion Júnior, Angela Maria Geraldo Pierin, Ines Lessa, Fernando Nobre
}

São Paulo, SP - Brazil

\begin{abstract}
Objective - To determine technical procedures and criteria used by Brazilian physicians for measuring blood pressure and diagnosing hypertension.
\end{abstract}

Methods - A questionnaire with 5 questions about practices and behaviors regarding blood pressure measurement and the diagnosis of hypertension was sent to 25,606 physicians in all Brazilian regions through a mailing list. The responses were compared with the recommendations of a specific consensus and descriptive analysis.

Results - Of the 3,621 (14.1\%) responses obtained, 57\% were from the southeastern region of Brazil. The following items were reported: use of an aneroid device by $67.8 \%$; use of a mercury column device by $14.6 \%, 11.9 \%$ of the participants never calibrated the devices; $35.7 \%$ calibrated the devices at intervals $<1$ year; $85.8 \%$ measured blood pressure in 100\% of the medical visits; $86.9 \%$ measured blood pressure more than once and on more than one occasion. For hypertension diagnosis, 55.7\% considered the patient's age, and only $1 / 3$ relied on consensus statements.

Conclusion - Despite the adequate frequency of both practices, it was far from that expected, and some contradictions between the diagnostic criterion for hypertension and the number of blood pressure measurements were found. The results suggest that, to include the great majority of the medical professionals, disclosure of consensus statements and techniques for blood pressure measurement should go beyond the boundaries of medical events and specialized journals.

Keywords: blood pressure measurement, calibration, hypertension

Unidade de Hipertensão Arterial do Hospital das Clínicas - Discipline of Nephrology of the FMUSP - Escola de Enfermagem da USP - Instituto de Saúde Coletiva da UFB e Hospital das Clínicas da FMUSP de Ribeirão Preto

Mailing address: Décio Mion Júnior - Instituto Central do Hospital das Clínicas - Disciplina de Nefrologia da FMUSP - Av. Dr. Enéas C. Aguiar, 255 - $7^{\circ}$ - S/7032 - 05403-000 - São Paulo, SP, Brazil - E-mail: demionjr@originet.com.br English version by Stela Maris C. e Gandour
Blood pressure measurement with the indirect method with the auscultatory technique is the most frequently used procedure in clinical practice for the diagnosis of arterial hypertension and assessment of the efficacy of treatment.

The international recommendations presented in the VI Joint National Committee on Prevention, Detection, Evaluation, and Treatment of High Blood Pressure ${ }^{1}$ by the World Health Organization and the International Society of Hypertension $^{2}$ point to principles that constitute the bases for correct measurement of blood pressure. Likewise, the III Brazilian Consensus on Hypertension ${ }^{3}$ recommends the routine for standardization of blood pressure measurement.

Preoccupation with standardization of blood pressure measurement is not a new fact. Since 1939, the American Heart Association ${ }^{4}$ has discussed the procedure and published recommendations in the years 1951, 1967, 1980, 1988, and $1993{ }^{5}$, the last with adjustments in $1997^{2}$. At each recommendation, new aspects related to the technician, equipment, patient, environment, and technique have been discussed aiming at eliminating the possibility of errors, which compromise the reliability of blood pressure measurement, and, consequently, the diagnosis of hypertension.

Of the errors regarding the equipment, lack of sphygmomanometer calibration stands out ${ }^{6,7}$. In regard to procedures, the frequency of blood pressure measurement during medical visits is low. In studies carried out in Salvador, in the state of Bahia, at different periods of time $(1984 \text { and 1993 })^{8,9}$, the authors reported that blood pressure was only recorded in $19 \%$ and $29 \%$ of the medical visits in the basic health network. In the city of São Paulo, considering 500 medical visits to a university-affiliated hospital, blood pressure readings occurred in $39 \%$ of the medical visits. In the city of Sorocaba, in the state of São Paulo, a study of the medical records of hypertensive patients showed that blood pressure had been recorded in $68 \%$ of the first medical visits ${ }^{10,11}$.

Another important aspect is the number of blood pressure measurements required for the diagnosis of hypertension, which was consensually recommended as at least 2 
readings on 2 or more occasions. Hypertension has been characterized as the permanent maintenance of mean values $\mathrm{m} \mathrm{140/90} \mathrm{mmHg}^{1-3}$. The diagnosis of hypertension, a disease affecting more than $20 \%$ of the adult population and up to $50 \%$ of the elderly population, depends on the type of practice related to the behavior of the professional and the diagnostic criterion. Even if asymptomatic, as in most hypertensive patients, hypertension accounts for an important reduction in life expectancy and quality of life, which are reasons sufficient to make blood pressure measurement, indeed, a routine medical procedure.

Despite the existing recommendations and the personal and social relevance of the problem, it is yet unknown how blood pressure is measured and the degree of medical adherence to the current consensus and guidelines in Brazil.

Considering all these highlighted issues, the objectives of this study were to determine how the basic technical procedures of blood pressure measurement and the operational criteria for the diagnosis of hypertension are used in daily medical practice.

\section{Methods}

In 1999, 25,606 questionnaires were sent to Brazilian physicians - general practitioners, cardiologists, and nephrologists - through a mailing list with responses being voluntary, covering the entire clinical registry of a large, national pharmaceutical manufacturer. The southeastern region, mainly the states of Rio de Janeiro and São Paulo, had a concentration of $50 \%$ of the registered professionals. Therefore, no intentional selection of the physicians who should receive/complete the questionnaires occurred, either by the investigators or by the manufacturer. The questionnaire comprised 5 simple questions, which required 3 minutes, at most, to answer, and encompassed practices and behaviors regarding blood pressure measurement and the diagnosis of hypertension as follows: 1) type of device used for blood pressure measurement; 2) frequency of calibration of the device used; 3 ) number of blood pressure measurements for the diagnosis of hypertension; 4) number of occasions on which blood pressure measurement was used for the diagnosis; 5) diagnosis of hypertension following the recommendations of the current consensus ${ }^{1,2}$. The following results were expected: a) that the aneroid device was the most frequently used, although the mercury column sphygmomanometer was the most indicated; b) that calibration of the devices was sporadic; $c$ ) that blood pressure measurement was performed at each and every medical visit; d) that the diagnosis was based on more than 1 measurement and on more than 1 occasion; and e) that the blood pressure cut point of ${ }^{3} 140 / 90 \mathrm{mmHg}$ was the criterion for the diagnosis of hypertension, according to current consensus. The analysis was descriptive.

\section{Results}

We received 3,621 (14.1\%) responses, 57\% of which were from the southeastern region, $22 \%$ from the southern region, $15 \%$ from the northeastern region, $5 \%$ from the west central region, and $1 \%$ from the northern region.

The aneroid sphygmomanometer was the most frequently used device (67.8\%); only $14.6 \%$ of the respondents used the mercury column device; the automated device was mentioned by only $1.8 \%$ of the respondents (tab. I). When 2 types of sphygmomanometer were considered, $413(77.8 \%)$ reported using both the aneroid and the mercury column devices. Calibration of the device in a period shorter than 1 year was reported by $35.7 \%$ of the respondents, while $32.3 \%$ calibrated the device only when it had a defect, and $11.9 \%$ never calibrated (tab. I).

The majority of the physicians $(85.8 \%)$ reported measuring blood pressure at all medical visits, and $86.9 \%$ reported measuring it more than once on different occasions to establish the diagnosis of hypertension. In regard to classifying the patients as hypertensive, for more than half of the respondents $(55.7 \%)$, age was an important element in selecting the cut points for blood pressure levels

\begin{tabular}{|c|c|c|}
\hline \multicolumn{3}{|c|}{$\begin{array}{l}\text { Table I - Devices used for blood pressure measurement and } \\
\text { calibration periodicity }\end{array}$} \\
\hline Variables & $\mathrm{N}^{\mathrm{o}}$ & $\%$ \\
\hline \multicolumn{3}{|l|}{ Type of device: } \\
\hline$\cdot$ aneroid & 2,457 & 67.8 \\
\hline - Hg column & 529 & 14.6 \\
\hline - automated & 64 & 1.8 \\
\hline - 2 types & 531 & 14.7 \\
\hline - 3 types & 25 & 0.7 \\
\hline - no information & 15 & 0.4 \\
\hline \multicolumn{3}{|l|}{ Calibration periodicity: } \\
\hline$\bullet<1$ year & 1,293 & 35.7 \\
\hline$\cdot \geq 1$ year & 699 & 19.3 \\
\hline - never calibrated & 431 & 11.9 \\
\hline - when required & 1,168 & 32.3 \\
\hline - no information & 30 & 0.8 \\
\hline
\end{tabular}

\begin{tabular}{|c|c|c|}
\hline \multicolumn{3}{|c|}{$\begin{array}{c}\text { Table II - Behavior of the professionals in regard to blood pressure } \\
\text { measurement }\end{array}$} \\
\hline Variables & $\mathrm{N}^{\mathrm{o}}$ & $\%$ \\
\hline \multicolumn{3}{|l|}{ Measure blood pressure in: } \\
\hline - $100 \%$ of the cases & 3,107 & 85.8 \\
\hline - $75 \%$ of the cases & 430 & 11.9 \\
\hline - $50 \%$ of the cases & 54 & 1.5 \\
\hline - $25 \%$ of the cases & 18 & 0.5 \\
\hline - no information & 12 & 0.3 \\
\hline \multicolumn{3}{|l|}{ Base their diagnosis on: } \\
\hline - 1 measurement on 1 occasion & 40 & 1.1 \\
\hline - more than 1 measurement on 1 occasion & 321 & 8.9 \\
\hline - more than 1 measurement on more than 1 occasion & 3,147 & 86.9 \\
\hline - 2 or more alternatives & 95 & 2.6 \\
\hline - no response & 18 & 0.5 \\
\hline \multicolumn{3}{|l|}{ Used as a diagnostic criterion: } \\
\hline - blood pressure $\geq 140 / 90 \mathrm{mmHg}$ & 1,176 & 32.5 \\
\hline - blood pressure $\geq 160 / 95 \mathrm{mmHg}$ & 361 & 10 \\
\hline - relies on age & 2,017 & 55.7 \\
\hline - 2 or more of the above possibilities & 27 & 0.7 \\
\hline - no response & 40 & 1.1 \\
\hline
\end{tabular}


(tab. II); on the other hand, only $32.5 \%$ used the recommended criterion of blood pressure $\mathrm{m} 140 / 90 \mathrm{mmHg}$.

\section{Discussion}

Contrary to data in the national literature ${ }^{8-11}$, the most important finding in this study was the high frequency of blood pressure measurement reported at most medical visits $(85.8 \%)$, even though far from that which should be required, ie, blood pressure measurement in $100 \%$ of the patients.

The remaining issues approached are the first national results that emphasize the correct attitude in accordance with the consensus, when most professionals $(86.9 \%)$ report the use of more than 1 blood pressure measurement on more than 1 occasion for the diagnosis of hypertension. This recommendation is required because of the characteristic blood pressure fluctuations ${ }^{10}$. Reeves ${ }^{12}$, when considering this aspect, reported that blood pressure varies both from minute to minute with a standard deviation of approximately $4 \mathrm{mmHg}$ for the systolic reading and $2-3 \mathrm{mmHg}$ for the diastolic reading, and throughout the day and on different days, with a variation of 5-12 $\mathrm{mmHg}$ for systolic blood pressure and 6-8 $\mathrm{mmHg}$ for diastolic blood pressure. On the III Brazilian Consensus on Hypertension ${ }^{3}$, it was agreed that, at each medical visit, blood pressure should be measured at least twice at 1-to-2minute intervals; if the diastolic pressure values differed by 5 $\mathrm{mmHg}$ or more, new measurements should be taken until the difference was lower than that value. According to the patient's clinical condition, the measurements should be repeated at least at 2 or more medical visits; on the first evaluation, blood pressure should be taken on both upper limbs with the patient seated or lying down, or both.

As expected, the aneroid sphygmomanometer was the most commonly used device, even though with no concern in regard to its calibration, which was reported as being performed in a period shorter than 1 year by only $1 / 3$ of the respondents. Currently, the choice of the proper device for blood pressure measurement is widely discussed. When the aneroid device is chosen, the difficulty in calibrating the manometer should be highlighted. By the end of the 1990s, in São Paulo, $60 \%$ of the aneroid devices and $21 \%$ of the mercury column devices were found not to be calibrated ${ }^{6}$. The recommended calibration periodicity is at least once every 6 months, and the aneroid device should be counterchecked with an adequately calibrated mercury column device. For aneroid manometers, the alignment of the needle with the zero point does not mean that the device is calibrated; on the other hand, in the mercury column device, if the meniscus is in that position, the calibration is adequate. The wide use of aneroid sphygmomanometers may perhaps be justified by their convenient size and weight, which facilitate their transportation.

Negative aspects of the use of mercury column devices have been discussed. O'Brien ${ }^{13,14}$ foretells that sphygmomanometry will undergo changes in this millennium due to mercury toxicity to the environment, and that, once its use is abolished, less resistance to the introduction of kilo-
Criteria for hypertension adopted by Brazilian physicians

pascal as a unit for blood pressure measurement will occur. Holland and Sweden do not allow the use of mercury devices in hospitals, preferring the aneroid or automated devices. The latter represent an alternative, as long as accurate and abiding by the operational rules recommended by the British Hypertension Society and the Association for the Advancement of Medical Instrumentation ${ }^{15}$. However, a recent survey evaluating devices used in ambulatory blood pressure monitoring in 3 epidemiological studies showed that 14 values of systolic blood pressure, among which 4 in the range from 140 to $160 \mathrm{mmHg}$, were persistently omitted by the devices ${ }^{16}$. It is worth noting that a number of automated devices were designed for blood pressure measurement by the patient at home and the routine use in hospitals or in clinical practice is the one to be assessed. In addition, most devices use the oscillometric method for blood pressure measurement, which is not appropriate in conditions of complex arrhythmias. Undoubtedly, in the near future, automated devices will tend to replace the indirect method based on the auscultatory technique, reducing the possibility of errors inherent to the device and the observer.

As a diagnostic parameter, most respondents adopt age and not the cut points of blood pressure values recommended by consensus statements. This preference leads to an underestimation of the diagnosis (false negative) in the population assisted, consequently delaying the treatment and its benefits, such as a reduction in cardiovascular morbidity and mortality.

This study does not include all clinical specialties, but those whose professionals account for blood pressure measuring in daily medical practice. This does not invalidate the results, but the external validity is impaired by the limitation of the origin of the participants from a single registry. However, even with a response rate of $14.1 \%$, the size of the respondent case series would have been sufficient to extrapolate the results for the country, had the sample been probabilistic. Despite the facilities provided for questionnaire return, the anonymity of the responses, and just one professional category (physicians) being targeted, the expected cooperation did not occur. More than half of the responses came from the southeastern region, to where $50 \%$ of the mailing was sent. Even when the interviewees are gathered at a professional event, the high frequency of lack of response and concentration of the responses by professionals living in the region or in the place housing the inquiry have been recently observed in Brazil, when assessing some type of knowledge related to medical practice ${ }^{17}$. The response rate to questionnaires sent by mail is usually low and varies with the focus and the disease being investigated. In an approach similar to that in this study, the response rate reached $67 \%$ in Canada ${ }^{18}$ in 1997 , and $34 \%$ in Houston ${ }^{19}$, in the United States, in 2000. The negative behavior of the Brazilian professional is probably due to not recognizing the value of their responses for understanding the national reality in regard to such an important problem as hypertension.

Anonymity theoretically would avoid the nonres- 
ponse bias due to not knowing the techniques and the consensus statements considered in this study. To suppose the existence of bias resulting from the origin of the responses of the professionals, who would consider themselves better informed, is not in accordance with the important observation that was the discordance in regard to the correct information concerning the number of blood pressure measurements and the occasions required for that measurement, and the incorrect information concerning the criterion for the diagnosis of hypertension and the periodicity of device calibration. To suppose that the southern and southeastern professionals were the major respondents theoretically because they were the most updated professionals does not seem to be true. In a national experience with the previously reported investigation conducted in the northeastern region, the professionals of that area were those who adhered most to the inquiry ${ }^{17}$. Therefore, it is not known whether the results would be similar, had the sample been probabilistic and originated from a large registry of professionals, such as that of the Brazilian Medical Association, even though that should be the best sampling alternative. However, this report is particularly relevant mainly due to the lack of national data that may serve as a start or alert, or both, for similar investigations in the country, and due to the fact that the responses, as suggested by the authors, may undergo validation tests.

The investigation revealed that aspects inherent in the blood pressure measurement procedure and diagnostic criteria of hypertension need to be reinforced in the medical population of the country, through means of information other than congresses and specialized events. Medical journals are limited to the medical population. The continuous education of health professionals remains a possibility for informing and updating, but other forms of wider information disclosure more appropriate to the profile of the Brazilian physicians should be encouraged.

\section{Acknowledgments}

To Roche Laboratories for their support.

\section{References}

1. The Sixth Report of the Joint National Committee on Prevention, Detection, Evaluation, and Treatment of High Blood Pressure. Arch Intern Med 1997; 157 : 2413-46.

2. World Health Organization. International Society of Hypertension Guidelines for the Management of Hypertension. J Hypertens 1999; 17: 151-83.

3. III Consenso Brasileiro de Hipertensão Arterial. Rev Bras Clin Terap 1998; 24 : 231-72.

4. Barker MH, Erlanger J, Meakins J, et al. Standartization of blood pressure readings. Am Heart J 1939; 17: 95-101.

5. PerloffD, Grim C, Flack J, Frohlich ED, et al. Human blood pressure determination by sphygmomanometry. Circulation 1993; 88: 2460-70.

6. Mion D, Pierin A. How accurate are sphygmomanometers? J Hum Hypertens 1998; 12: 245-48.

7. Burke M, Towers HM, O'Malley K, Fitzgerald DJ, O'Brien ET. Sphygmomanometers in hospital and family practice: problems and recommendations. BrMed J 1982; 285: 469-71.

8. Lessa I, Cortes, E, Menezes G, Lima MEC, Santos CMC, etal. A medida da pressão arterial na prática médica de rotina. Rev Assoc Med Bras 1984; 30: 50-2.

9. Lessa I, Costa MC, Daltro E. Diferenças das freqüências da medida da pressão arterial em primeiras consultas de adultos pré e pós implantação do Programa Nacional de Controle da Hipertensão. Rev Assoc Med Brasil 1993; 39: 141-5.

10. Alavarce DC, Pierin A, Mion D. A pressão arterial está sendo medida? Rev Esc Enf USP 2000; 34: 84-90.

11. Cabral AH. Caracterização dos hipertensos atendidos na unidades básicas de saúde da cidade de Sorocaba. São Paulo, 2000. Dissertação de mestrado, Escola deEnfermagem daUSP.

12. Reeves RA. Does this patient have hypertension? How to measure blood pressure. JAMA 1995; 273: 1211-8.

13. O'Brien E. Will mercury manometers soon be obsolete? J Human Hypertens 1995; 9: 933-4

14. O'Brien E. Replacing the mercury sphygmomanometer: requires clinicians to demand better automated devices. Br Med J 2000; 320: 815-6.

15. O'Brien E, Petrie J, Littler WA, et al. The British Hypertension Society Protocol for the evaluation of blood pressure measuring devices. J Hypertens 1993; 1(suppl 2) S43-63.

16. Rose KM, Arnett DK, Ellison RC, Heiss G. Skip patterns in DINAMAPmeasured blood pressure in 3 epidemiological studies. Hypertension 2000; 35 : 1032-6.

17. Santos RD, Andrei C, Spósito JES, et al. Programa de Avaliação Nacional do Conhecimento sobre Prevenção da Aterosclerose (PANDORA): um questionário entre cardiologistas brasileiros sobre redução do colesterol. Arq Bras Cardiol 2000; 75: 289-302.

18. McAlister FA, Laupacis A, Teo KK, Hamilton PG, Montague TJ. A survey of clinician attitudes and management practices in hypertension. J Hum Hypertens 1997; 11: 413-9.

19. Hyman DJ, Pavlik VN. Self-reported hypertension treatment practices among primary care physicians: blood pressure thresholds, drug choices, and the role of guidelines and evidence based medicine. Arch Intern Med 2000; 160: 2281-6. 